T. C. Skinner $\cdot$ H. Hoey $\cdot$ H. M. McGee •

S. E. Skovlund · Hvidøre Study Group on Childhood

Diabetes

\title{
A short form of the Diabetes Quality of Life for Youth questionnaire: exploratory and confirmatory analysis in a sample of 2,077 young people with type 1 diabetes mellitus
}

Received: 5 July 2005 / Accepted: 31 August 2005 / Published online: 26 January 2006

(C) Springer-Verlag 2006

\begin{abstract}
Aims/hypothesis: The aim of this study was to test the construct validity of the Diabetes Quality of Life for Youth (DQOLY) questionnaire in a large representative sample of young people with type 1 diabetes mellitus. Methods: The 52-item DQOLY questionnaire was completed by 2,077 adolescent individuals (aged 10-18 years) with type 1 diabetes. Participants were recruited from 22 paediatric diabetes centres in 18 countries across Europe, Asia and North America. $\mathrm{HbA}_{1 \mathrm{c}}$ levels were determined once and analysed centrally. Results: Exploratory factor analysis generated three possible measurement models of a revised questionnaire, two with four factors and one with six factors, with all models indicating the presence of one satisfaction scale, but with many of the impact and worry scale items either double loading or not loading on any factors. Subsequent confirmatory analysis indicated that compared with the original DQOLY scales, the six-factor solution was the best-fitting model. Conclusions/interpretation: The DQOLY factor structure does not show construct validity in a large, diverse representative sample of young people with type 1 diabetes. However, a revised (short-form) version of the DQOLY is proposed that has improved construct validity, adequate internal consistency, and more precise
\end{abstract}

T. C. Skinner $(\bowtie)$

School of Psychology, University of Southampton,

Southampton, UK

e-mail: t.c.skinner@soton.ac.uk

Tel.: +44-2380-594588

H. Hoey

Ireland Department of Paediatrics, Trinity College,

National Children's Hospital,

Dublin, Ireland

H. M. McGee

Department of Psychology,

Royal College of Surgeons in Ireland,

Dublin, Ireland

S. E. Skovlund

Novo Nordisk,

Bagsværd, Denmark and hypothesised association with $\mathrm{HbA}_{1 \mathrm{c}}$. It is anticipated that this shorter version will enhance the acceptability and clinical utility of the measure, making it more feasible to introduce as part of routine care.

Keywords Adolescents · Quality of life · Type 1 diabetes - Validity

Abbreviations CFI: comparative fit index - DCCT: diabetes control and complications trial - DQOL: diabetes quality of life (questionnaire) - DQOLY: diabetes quality of life for youth (questionnaire) - NFI: normed fit index . RMSEA: root mean square error approximation

\section{Introduction}

Since publication of the Diabetes Control and Complications Trial (DCCT) results [1] it has been widely accepted that improving metabolic control must be a fundamental priority in type 1 diabetes mellitus care. However, recognising the distinctive treatment-related characteristics of adolescents, DCCT researchers separately examined the effectiveness of the intervention in the adolescent cohort (aged 13-17 years at entry) [2]. As in the full sample, the risk both of the onset and of progression of diabetic complications was significantly reduced in the adolescent intensive intervention group, compared with the conventional treatment group. Achieving near-normal glycaemic levels proved to be difficult and also heightened the risk of hypoglycaemia.

In the adult sample, the increased burden of intensive management and the increased rates of hypoglycaemia were not associated with poorer diabetes-related quality of life as assessed with the Diabetes Quality of Life (DQOL) questionnaire [3]. However, separate analysis of the DCCT data on the adolescent (aged 13-17 years at entry) subsample did show decreased school satisfaction and greater distress [4]. These results raised the question about the possibility of an association between glycaemic control and adolescent quality of life. 
The DCCT used the DQOL, with some additional items for adolescents. This was revised to become the 52-item Diabetes Quality of Life for Youth (DQOLY) scale [5]. Subsequent studies with adolescents have not consistently supported the idea of an association between quality of life and metabolic control in adolescents with diabetes [6-9].

One potential cause of this is that the published research has yet to consider the construct validity of the DQOLY. The first step towards demonstrating this is to test whether the internal structure of the measure is valid, i.e. to verify that items purportedly assessing a single construct do indeed assess that construct, and that items on different scales are not assessing the same underlying construct. If the DQOLY does not have good internal construct validity, it cannot be an accurate measure of diabetes-related quality of life in adolescents.

At 52 items the DQOLY is a lengthy instrument, which limits its clinical utility. Therefore the aim of the current study was to examine the construct validity of the DQOLY and to examine the possibility of developing a shorter version and thereby enhancing its measurement properties and clinical utility.

\section{Subjects and methods}

Subjects

This study was a multicultural cohort study, conducted using 22 centres in 18 countries in Europe, Japan and North America. Type 1 diabetic patients who were born between 1980 and 1987 were invited to participate between March and August 1998 at each study centre. The patients were all aged between 10 and 18 years at the beginning of the study, with informed consent provided by all participants, and parents where appropriate. The average age of patients was $14.3 \pm 2.1$ years. As a result 2,101 patients consented and 2,077 had their $\mathrm{HbA}_{1 \mathrm{c}}$ measurements taken (for full details of recruitment and demographics see [9]).

\section{Procedure}

The study was performed according to the criteria of the Helsinki II declaration, and ethical approval was obtained from the relevant regulatory or institutional Ethics Committee in each country and centre. Written informed consent for questionnaires and blood samples was obtained from patients and their families. Samples and information were obtained from $79 \%$ of the patients. All questionnaires were completed confidentially and returned in a sealed envelope during a routine clinic visit. All questionnaires were forwarded to the coordinating centre and were received within 2 to 3 weeks of blood collection for $\mathrm{HbA}_{1 \mathrm{c}}$.

\section{Clinical data}

Age, sex, height, weight, age at diagnosis, number of insulin injections, use of premixed insulin, total daily insulin dose, number of serious hypoglycaemic incidents (i.e. convulsions or unconsciousness) in the last 3 months, family structure and ethnic status were recorded. Ethnic minority was defined as a minority group differentiated from the main population of the community by racial or cultural background. Approximately $10 \%$ of the population were described as ethnic minority groups in their respective countries in Europe and Japan. Ethnic status was not deemed categorisable in this way in Canada $(n=224)$ due to the multicultural nature of the population. Family structure was defined by whether none, one or both parents lived at home.

\section{Blood samples}

Each patient took a blood test, which was sent to the Steno Diabetes Center (Gentofte, Denmark) for determination of $\mathrm{HbA}_{1 \mathrm{c}}$. The normal range of $\mathrm{HbA}_{1 \mathrm{c}}$ in non-diabetics is 4.4$6.3 \%$ with a mean of $5.4 \%$. Details of the transportation of specimens have been published previously [10].

\section{Measures}

The DQOLY questionnaire as developed by Ingersoll and Marrero [5] was used to assess the quality of life in adolescents. The questionnaire consists of 52 items, divided into four sections, with one single separate item, i.e.: impact of diabetes (23 items); worries about diabetes (11 items); satisfaction with treatment (10 items); and satisfaction with life (seven items); plus one single item on health perception. Questions were scored using a five-point Likert scale, with the exception of health perception, which was measured using a four-point Likert scale. Lower scores indicated a poorer quality of life. For ease of comparison across subscales, items on all subscales were scored in the same direction.

Fourteen languages were used in the study. The questionnaires were translated from English to native languages by a bilingual professional translator. This was then back translated by a second independent bilingual professional translator. The back translation was compared with the original version and was sent to two members of the research team for comparison. Any discrepancies were resolved between translators, and lay panel testing was performed on five or six adolescents in each country. Any difficulties were discussed and resolved between translators and the research team. Item and questionnaire completion rates and Cronbach's alpha values indicating internal consistency of subscales demonstrated that the questionnaires were acceptable across the whole population sampled (for full details see Hoey et al. [9]). 
Statistical analyses

The data were initially split into two separate datasets, using SPSS v11.1 to select a random 50\% sample from the dataset. The first dataset was then used to conduct exploratory analysis, and the second dataset to conduct confirmatory analysis. The exploratory factor analysis was undertaken to identify one or more data structures that met the criteria for simple structure, that is all items loaded $>0.4$ on only one factor, and to confirm that the items loadings were theoretically coherent. Analysis was conducted using principal-components analyses with direct oblimin rotation. Initial factor selection was based on eigenvalues $>1$. Thereafter, factor selection was based on interpretation of the scree plots (looking for the point of inflection), and on the need for items to load $>0.4$ on only one factor, and for scales to be theoretically coherent. Items that double loaded $>0.4$ or did not load on any factor $>0.4$ were removed and the factor analysis was repeated. Two distinct analyses were undertaken, one on the whole sample, with the second repeating the analysis on splitting the file into tertiles, based on age, and establishing an item structure that was consistent across all three age bands.

Confirmatory analysis was conducted by structural equation modelling, conducted using AMOS v5, using analysis of the correlation matrix. Although a non-significant $\chi^{2}$ is frequently used for assessing goodness of fit, this statistic is considered overly sensitive in large sample sizes, and was therefore not used here. Therefore three fit indices were used: the comparative fit index (CFI), which should be $>0.9$ for a good fit; the normed fit index (NFI), which should be $>0.9$ for a good fit; and the root mean square error approximation (RMSEA), which should be $<0.05$ for a good fit. For all models, the basic model as specified by the factor analysis was entered, and then this was optimised in line with suggested modifications from the output, by allowing covariance between items on the same factor but not across factors and allowing covariance between factors. All figures cited are for the optimised models. Selection of the final measurement model was determined by examining the three fit indices, and choosing the model with the best indices. All correlations and $t$ tests were accepted as significant at $p<0.05$.

\section{Results}

\section{Exploratory factor analysis}

Factor analysis of dataset 1 generated seven factors with an eigenvalue $>1$. However, examination of the scree plot, which seemed to have two distinct points of inflection, suggested that two different factor structures, one with four and one with six factors, may provide a simple structure. Therefore, two models were generated from this process, a summary of which can be found in Table 1 . In both models the items from the treatment satisfaction and the life satisfaction loaded on to one scale. In the four-factor model the three remaining factors were labelled parental control (three items), impact (eleven items) and future worries (seven items). In the six-factor model the same items are included but now distributed across five factors, consisting of parental control (three items), future worries (seven items), impact of treatment (three items), impact of symptoms (three items) and impact on activities (five items). This four-factor model accounted for $42 \%$ of the variance in the included items, with the six-factor model accounting for $53 \%$ of the variance in the included items.

Subsequently, to explore and remove any developmental effects in factor structures, models were developed for each of the age groups (derived on the basis of a tertile split to ensure adequate numbers in each group for analysis), 10 $13,13-15$ and 15-19 years. Thereafter, only those items that loaded consistently in all three age groups, and loaded on to the same factor in all three age groups, were compiled to generate a final age-congruent model. This generated a second four-factor model, which is summarised in Table 1 and which contained the satisfaction items all loading on one scale, the same seven-item worry scale as generated in the other factor analysis and the parental concerns factor. The fourth factor was a seven-item impact factor. This model accounted for $46 \%$ of the variance in the included items.

\section{Confirmatory factor analysis}

First the original four-factor structure of the DQOLY questionnaire was entered and optimised to examine the fit of the model to the second dataset in this study. In addition, a second analysis was run with the two satisfaction scales combined to form one satisfaction scale, but retaining the two original impact and worry scales from the DQOLY. Thereafter, the three models generated by the exploratory analysis were fitted to the data and optimised. The results of the optimised analysis are summarised in Table 2.

From Table 2, it would appear that the six-factor model derived from the exploratory analysis would seem to provide the best-fitting measurement model for the items in the DQOLY, with two out of the three indices meeting the criteria of a good fit. None of the other models had single-fit indices meeting the criteria for a good fit, despite robust attempts to optimise the model within the constraints specified.

The scales are significantly correlated with the exception of satisfaction and parental concern (see Table 3). However, all the correlations are moderate to low, and indicate that the scales assess different constructs. The reliability coefficients as measured by Cronbach's alpha are within the acceptable range. The future worries scale had a Cronbach's alpha of 0.82 ( 0.84 for the DQOLY worry scale in this sample), the parental influence scale had a Cronbach's alpha of 0.79 and the impact on activities scale had a Cronbach's alpha of 0.65 , all of which are considered adequate for the number of items in the scales. The symptom impact scale had a Cronbach's alpha value of 0.51 , and the impact of treatment scale had a Cronbach's alpha of 0.47 , which is satisfactory for subscales containing 
Table 1 Results of exploratory factor analysis and DQOLY proposed factor structure

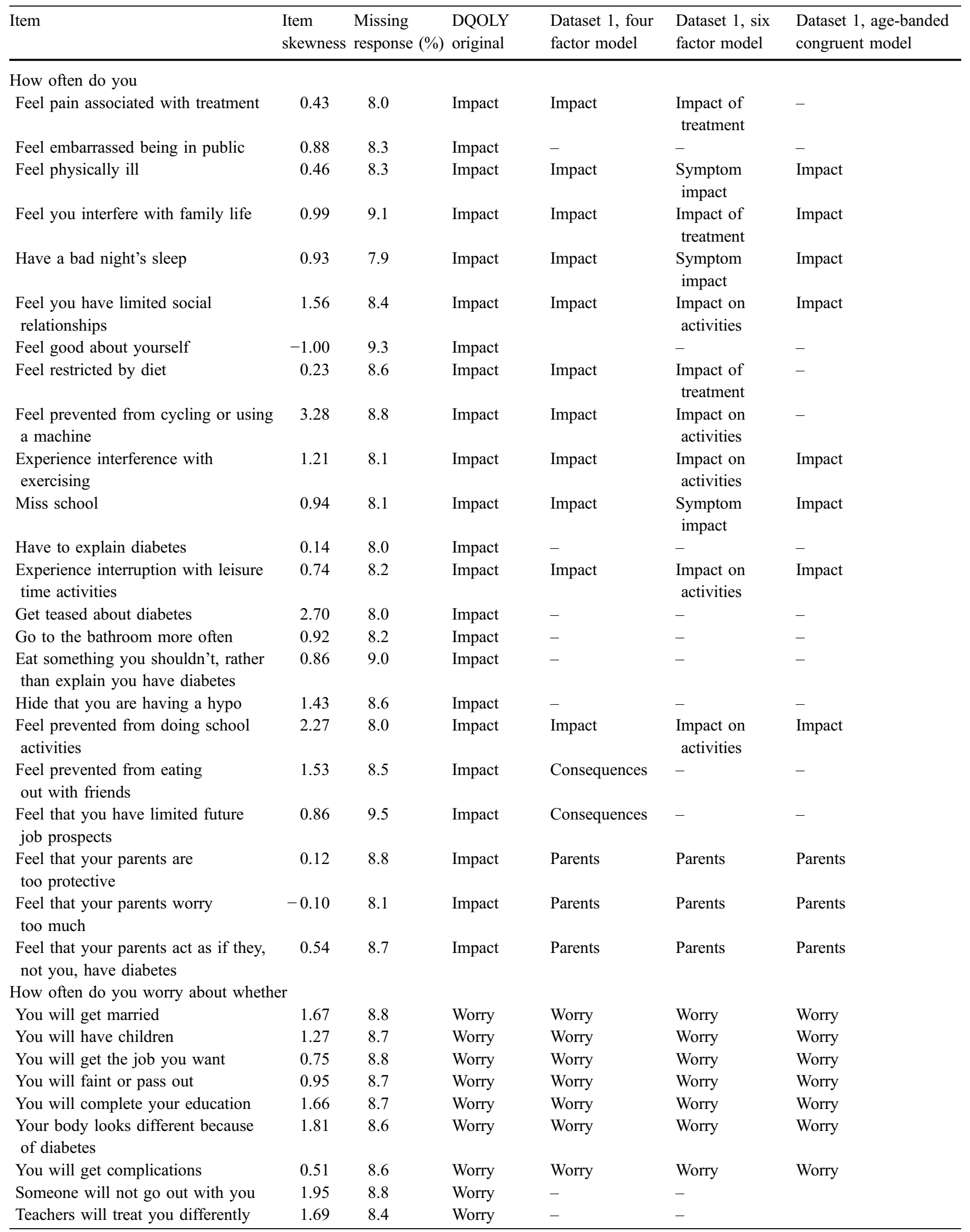


Table 1 (continued)

\begin{tabular}{|c|c|c|c|c|c|c|}
\hline Item & $\begin{array}{l}\text { Item } \\
\text { skewness }\end{array}$ & $\begin{array}{l}\text { Missing } \\
\text { response (\%) }\end{array}$ & $\begin{array}{l}\text { DQOLY } \\
\text { original }\end{array}$ & $\begin{array}{l}\text { Dataset } 1 \text {, four } \\
\text { factor model }\end{array}$ & $\begin{array}{l}\text { Dataset } 1 \text {, six } \\
\text { factor model }\end{array}$ & $\begin{array}{l}\text { Dataset } 1 \text {, age-banded } \\
\text { congruent model }\end{array}$ \\
\hline $\begin{array}{l}\text { Your diabetes will disrupt something } \\
\text { in school }\end{array}$ & 1.65 & 8.5 & Worry & - & - & \\
\hline You are behind developmentally & 1.73 & 8.6 & Worry & - & - & \\
\hline \multicolumn{7}{|l|}{ How satisfied are you with } \\
\hline Time taken to manage diabetes & 0.63 & 9.4 & $\begin{array}{l}\text { Treatment } \\
\text { satisfaction }\end{array}$ & Satisfaction & Satisfaction & Satisfaction \\
\hline Time getting check-ups & 0.78 & 8.8 & $\begin{array}{l}\text { Treatment } \\
\text { satisfaction }\end{array}$ & Satisfaction & Satisfaction & Satisfaction \\
\hline $\begin{array}{l}\text { Time needed to monitor your blood } \\
\text { glucose }\end{array}$ & 0.81 & 8.8 & $\begin{array}{l}\text { Treatment } \\
\text { satisfaction }\end{array}$ & Satisfaction & Satisfaction & Satisfaction \\
\hline Current treatment & 1.22 & 8.9 & $\begin{array}{l}\text { Treatment } \\
\text { satisfaction }\end{array}$ & Satisfaction & Satisfaction & Satisfaction \\
\hline Flexibility of diet & 0.83 & 8.8 & $\begin{array}{l}\text { Treatment } \\
\text { satisfaction }\end{array}$ & Satisfaction & Satisfaction & Satisfaction \\
\hline $\begin{array}{l}\text { Burden your diabetes places on your } \\
\text { family }\end{array}$ & 0.67 & 10.8 & $\begin{array}{l}\text { Treatment } \\
\text { satisfaction }\end{array}$ & Satisfaction & Satisfaction & Satisfaction \\
\hline Knowledge of your disease & 1.42 & 8.9 & $\begin{array}{l}\text { Treatment } \\
\text { satisfaction }\end{array}$ & Satisfaction & Satisfaction & Satisfaction \\
\hline Sleep & 1.34 & 8.9 & $\begin{array}{l}\text { Life } \\
\text { satisfaction }\end{array}$ & Satisfaction & Satisfaction & Satisfaction \\
\hline Social relationships & 1.97 & 8.9 & $\begin{array}{l}\text { Life } \\
\text { satisfaction }\end{array}$ & Satisfaction & Satisfaction & Satisfaction \\
\hline Work and school & 1.30 & 9.2 & $\begin{array}{l}\text { Life } \\
\text { satisfaction }\end{array}$ & Satisfaction & Satisfaction & Satisfaction \\
\hline Appearance of body & 0.89 & 9.2 & $\begin{array}{l}\text { Life } \\
\text { satisfaction }\end{array}$ & Satisfaction & Satisfaction & Satisfaction \\
\hline Time spent exercising & 0.94 & 9.2 & $\begin{array}{l}\text { Life } \\
\text { satisfaction }\end{array}$ & Satisfaction & Satisfaction & Satisfaction \\
\hline Leisure time & 1.42 & 9.3 & $\begin{array}{l}\text { Life } \\
\text { satisfaction }\end{array}$ & Satisfaction & Satisfaction & Satisfaction \\
\hline Life in general & 1.18 & 9.1 & $\begin{array}{l}\text { Life } \\
\text { satisfaction }\end{array}$ & Satisfaction & Satisfaction & Satisfaction \\
\hline Performance at school & 0.93 & 9.4 & $\begin{array}{l}\text { Life } \\
\text { satisfaction }\end{array}$ & Satisfaction & Satisfaction & Satisfaction \\
\hline How classmates treat you & 1.61 & 9.1 & $\begin{array}{l}\text { Life } \\
\text { satisfaction }\end{array}$ & Satisfaction & Satisfaction & Satisfaction \\
\hline School attendance & 1.47 & 9.8 & $\begin{array}{l}\text { Life } \\
\text { satisfaction }\end{array}$ & Satisfaction & Satisfaction & Satisfaction \\
\hline
\end{tabular}

only three items. As the three impact scales were inter- the four-factor model generated through factor analysis, the correlated, and the same items make up one impact scale in structural modelling was repeated, introducing a second,

Table 2 Optimised goodness of fit indices

\begin{tabular}{|c|c|c|c|c|c|}
\hline & $\chi^{2}$ & $d f$ & CFI & NFI & RMSEA \\
\hline DQOLY original & 4539 & 1141 & 0.753 & 0.698 & 0.061 \\
\hline DQOLY revised ${ }^{\mathrm{a}}$ & 4397 & 1128 & 0.762 & 0.707 & 0.060 \\
\hline Four-factor model & 2978 & 634 & 0.850 & 0.815 & 0.065 \\
\hline Six-factor model & 1419 & 573 & 0.923 & 0.879 & 0.043 \\
\hline Age-congruent model (four factors) & 2713 & 527 & 0.847 & 0.821 & 0.075 \\
\hline
\end{tabular}

${ }^{a}$ The revision consisted of merging the two satisfaction scale into one factor 
Table 3 Correlations between DQOLY scale scores

\begin{tabular}{llllll}
\hline & $\begin{array}{l}\text { Future } \\
\text { worries }\end{array}$ & $\begin{array}{l}\text { Parental } \\
\text { concern }\end{array}$ & $\begin{array}{l}\text { Impact on } \\
\text { activities }\end{array}$ & $\begin{array}{l}\text { Impact of } \\
\text { treatment }\end{array}$ & $\begin{array}{l}\text { Symptom } \\
\text { impact }\end{array}$ \\
\hline Parental concern & $0.335^{* *}$ & & & & \\
Impact on activities & $0.305^{* *}$ & $0.210^{* *}$ & & & \\
Impact of treatment & $0.242^{* *}$ & $0.244^{* *}$ & $0.408^{* *}$ & & \\
Symptom impact & $0.241^{* *}$ & $0.137^{* *}$ & $0.365^{* *}$ & $0.392^{* *}$ & \\
Satisfaction & $0.285^{* *}$ & 0.047 & $0.223^{* *}$ & $0.240^{* *}$ & $0.188^{* *}$ \\
\hline
\end{tabular}

$* * p<0.001$ for correlation (two-tailed) consistency for the parental concern, worry and impact scale in each country (see Table 4).

The revised version is noticeably shorter than the original DQOLY; however, the scales seem to correlate well. The future worries scale correlated 0.95 with the full worry scale from the DQOLY. The impact scales correlated significantly with the DQOLY impact scale $(0.5<r>0.71$; $p<0.001)$. If the three impact and parental concerns are combined, this correlates 0.92 with the DQOLY original impact score, from which all items originated.

There are significant sex-related differences for five of the six subscales. These are summarised in Table 5, with girls having poorer scores than boys. Three of the subscales were correlated with age, older participants reporting less satisfaction with treatment $(r=0.19 ; p<0.001)$, greater impact of treatment $(r=0.12 ; p<0.001)$ and greater worry about the future $(r=0.18 ; p<0.001)$. ANOVA using age year (rounded up) as the independent variable did not indicate any significant quadratic trends with the new scales. Last, the association of the new scales with $\mathrm{HbA}_{1 \mathrm{c}}$ was explored. Correlations indicated that quality of life scales had significant associations with $\mathrm{HbA}_{1 \mathrm{c}}$. To explore this relationship more fully, a stepwise linear regression was undertaken, entering age and sex on step 1, and then all quality of life scales on step 2 (using stepwise entry). Age and sex accounted for $1.4 \%$ of the variance in $\mathrm{HbA}_{1 \mathrm{c}}$ $(F=12.33 ; d f=2 ; p<0.001)$. Of the quality of life scales, symptom impact, future worries and impact on activities were significant predictors of $\mathrm{HbA}_{1 \mathrm{c}}$, contributing an additional $3.5,0.9$ and $0.8 \%$ variance, respectively, to the prediction of $\mathrm{HbA}_{1 \mathrm{c}}$ (total equation $R=0.066 ; F=24.13$; $d f=5 ; p<0.001)$.

\section{Discussion}

Using both exploratory factor analysis and confirmatory structural modelling the original structure of the DQOLY was broadly supported. No items cross-loaded from one subscale onto an alternative scale in this analysis. Furthermore, this analysis identifies a possible new shortform DQOLY that has good construct validity, is equally valid for both sexes, and seems be internally consistent across countries.

The 11-item worry scale appeared to contain a number of redundant items, and is better represented by a seven-item scale. The 24-item impact scale from the original DQOLY also appeared to contain a number of redundant items, with 
Table $5 t$ tests comparing males and females on revised DQOLY scales

${ }^{a}$ Equality of variance could not be assumed, so adjusted figures are presented

\begin{tabular}{|c|c|c|c|c|c|}
\hline & Mean & SD & $t$ & $d f$ & $p$ \\
\hline \multicolumn{6}{|c|}{ Future worries } \\
\hline Female & 1.8035 & 0.72238 & -4.71 & $1865^{\mathrm{a}}$ & 0.000 \\
\hline Male & 1.9653 & 0.76978 & & & \\
\hline \multicolumn{6}{|c|}{ Parental concern } \\
\hline Female & 2.8845 & 1.09463 & 2.28 & 1906 & 0.023 \\
\hline Male & 2.7677 & 1.14593 & & & \\
\hline \multicolumn{6}{|c|}{ Impact on activities } \\
\hline Female & 1.5766 & 0.52670 & 1.13 & 1892 & 0.259 \\
\hline Male & 1.5500 & 0.49644 & & & \\
\hline \multicolumn{6}{|c|}{ Impact of treatment } \\
\hline Female & 2.1993 & 0.68577 & -2.52 & 1900 & 0.012 \\
\hline Male & 2.2813 & 0.73233 & & & \\
\hline \multicolumn{6}{|c|}{ Symptom impact } \\
\hline Female & 1.8762 & 0.57265 & -2.75 & $1859^{\mathrm{a}}$ & 0.006 \\
\hline Male & 1.9527 & 0.64603 & & & \\
\hline \multicolumn{6}{|c|}{ Satisfaction } \\
\hline Female & 1.9231 & 0.69049 & -3.80 & $1723^{\mathrm{a}}$ & 0.000 \\
\hline Male & 2.0551 & 0.76197 & & & \\
\hline
\end{tabular}

the analysis suggesting that 11 of these items should be retained, generating four subscales.

The items for the life and treatment satisfaction scales would appear to be represented more accurately by a single satisfaction scale, which is problematic when it comes to recommending a shortened version for clinical use. Three options obviously present themselves: (1) drop assessment of satisfaction from the instrument; (2) keep the instrument diabetes-focused and retain the diabetes treatment satisfaction items; and (3) use this scale to look at broader quality of life issues and drop the satisfaction items. The recommendation here is to take the first option, and drop both satisfaction scales for a number of reasons:

(1) The diabetes satisfaction items overlap with content in the other scales. This poses challenges about how to manage discrepancies between satisfaction and impact or worry. If there is no discrepancy then some of the items are redundant.

(2) Keeping the life satisfaction items means the tool is no longer diabetes-specific. With the abundance of other satisfaction measures with arguably better developmental histories and psychometric properties, it would seem to make more sense to use these other tools.

(3) If the two scales are not distinct, how is it possible to be confident they are each measuring what they claim to, and are not measuring a third underlying dimension.

(4) Satisfaction is a discrepancy measure, the discrepancy between expectation and experience, posing interpretation problems, e.g. low expectations met can get the same score as high expectations met. This becomes even more problematic when scores change.

(5) The discrepancy nature of items may also explain the lack of separation in the two scales here, as the responses indicate a general discrepancy response rather than item- or domain-specific experience.

(6) Satisfaction scales are notorious for having ceiling effects, reducing their explanatory power, clinical utility and sensitivity to change.

When developing the shortened version of the DQOLY, the data were approached in a number of ways. Models were developed by analysing the whole dataset and by looking at three age groups and generating a measurement model that was congruent across these age-group congruent items. Although the shortened version of the DQOLY recommended here can be said to have construct validity (based on the analysis), face validity (from its development in earlier studies), and adequate internal consistency, further studies are required to address the criterion and predictive validity of the measure. With the impact scale being split into four factors, the clinical utility of these subscales particularly warrants further investigation. Given the abundance of data on the importance of the family in diabetes management for adolescents $[11,12]$, and the need to manage the transfer of responsibility from parents to children $[13,14]$, the parental concern scale may provide a useful tool to facilitate clinical discussion of this issue. The revised DQOLY recommended here is shorter, and could be shortened further by using the treatment satisfaction scale only, thereby keeping all items specific to diabetes. This would serve to increase the acceptability of the measures, further facilitating its clinical utility.

Given the large sample size, the presence of a correlation between these markers of health-related quality of life and $\mathrm{HbA}_{1 \mathrm{c}}$ is unsurprising. Here though, it is of note that the physical consequences subscale showed a noticeable stronger association than the other five scales. Furthermore, 
this is stronger than the association between the original DQOLY scales and $\mathrm{HbA}_{1 \mathrm{c}}$ (all less than $r=0.12$ ). Despite this, these correlations are small in nature and indicate that subjective experience of the impact of diabetes would appear to be distinct from the level of metabolic control.

This modified version generally exceeds the standard reliability coefficients and has both face and content validity. It is possible to use this modified version in adolescents of all ages as the items have been found to have no developmental trends, which could confound the quality of life scores. This allows for comparisons to be made between adolescents of different ages on a number of factors. In sum, it is anticipated that this shortened scale (designated the short-form DQOLY [DQOLY-SF]) will enhance the acceptability of assessing quality of life in adolescents with diabetes, making it more feasible to introduce as part of routine care.

Acknowledgements The Hvidøre Study Group on Childhood Diabetes (http://www.hvidoeregroup.org) is: Henk-Jan Aanstoot, Ijsselland Hospital, Capelle, the Netherlands; Francesco Chiarelli, Paediatric University Clinic, Chieti, Italy; Denis Daneman, Hospital for Sick Children, University of Toronto, Toronto, Canada; Thomas Danne, Charité, Humboldt University, Berlin, Germany; Harry Dorchy, University Children's Hospital, Queen Fabiola, Brussels, Belgium; Michael Fitzgerald, Department of Psychiatry, Trinity College, Dublin, Ireland; Patrick Garandeau, Institut Saint Pierre, Montpellier, France; Stephen Greene, University of Dundee, Dundee, UK; Hilary Hoey, Ireland Department of Paediatrics, Trinity College, National Children's Hospital, Dublin, Ireland; Reinhard Holl, University of Ulm, Ulm, Germany; Philip Hougaard, Novo Nordisk, Bagsværd, Denmark; Eero Kaprio, Peijas Hospital, Peijas, Finland; Mirjana Kocova, Paediatric Clinic-Skopje, Skopje, Republic of Macedonia; Helle Lynggaard, Novo Nordisk, Bagsværd, Denmark; Pedro Martul, Endocrinologia Pediatrica Hospital De Cruces, Cruces, Spain; Nobuo Matsuura, Kitasato University School of Medicine, Kitasato, Japan; Henrik B. Mortensen, Department of Pediatrics, Glostrup University Hospital, Glostrup, Denmark; Kenneth Robertson, Royal Hospital for Sick Children, Glasgow, UK; Eugen Schoenle, University Children's Hospital, Zurich, Switzerland; Oddmund Sovik, Haukeland Hospital, Bergen, Norway; Peter Swift, Leicester Royal Infirmary Children's Hospital, Leicester, UK; Rosa Maria Tsou, Hospital S. Joao, Porto, Portugal; Maurizio Vanelli, Department of Paediatrics, University of Parma, Italy; Jan Åman, Örebro Medical Center Hospital, Örebro, Sweden. This study group and this research project is supported by Novo Nordisk. The authors state that they are not aware of any duality of interest.

\section{References}

1. Diabetes Control and Complications Research Group (1994) Diabetes control and complications trial (DCCT): update. Diabetes Care 13:427-433

2. Diabetes Control and Complications Research Group (1994) Effect of intensive diabetes treatment on the development and progression of long-term complications in adolescents with insulin-dependent diabetes mellitus. J Pediatr 125:177-188

3. DCCT Research Group (1996) Influence of intensive diabetes treatment on quality-of-life outcomes in the diabetes control and complications trial. Diabetes Care 19:195-203

4. Madsen D, Roisman GI, Collins WA (2002) The intersection of adolescent development and intensive intervention: age-related psychosocial correlates of treatment regimens in the Diabetes Control and Complication trial. J Pediatr Psychol 27:451-459

5. Ingersoll GM, Marrero DG (1991) A modified quality of life measure for youths: psychometric properties. Diabetes Educ $17: 114-120$

6. Grey M, Boland EA, Yu C, Sullivan-Bolyai S, Tamborlane WV (1998) Personal and family factors associated with quality of life in adolescents with diabetes. Diabetes Care 21:909-914

7. Delamater AM (1998) Quality of life in youths with diabetes. Diabetes Spectrum 13:23-27

8. Guttmann-Bauman I, Flaherty BP, Strugger M, McEvoy RC (1998) Metabolic control and quality of life assessment in adolescents with IDDM. Diabetes Care 21:915-918

9. Hoey $\mathrm{H}$ et al for the Hvidøre Study Group on Childhood Diseases (2001) Good metabolic control is associated with better quality of life in 2,101 adolescents with type 1 diabetes. Diabetes Care 24:1923-1928

10. Mortensen HB, Hougaard P (1997) Comparison of metabolic control in a cross-sectional study of 2,873 children and adolescents with IDDM from 18 countries. The Hvidøre Study Group on Childhood Diabetes. Diabetes Care 20:714 720. Erratum in: Diabetes Care 1997 20:1216

11. Jacobson AM, Hauser ST, Lavori P et al (1994) Family environment and glycemic control: a four year prospective study of children and adolescents with insulin dependent diabetes mellitus. Psychosom Med 56:401-409

12. Kovacs M, Goldston D, Obrosky S, Iyengar S (1994) Prevalence and predictors of pervasive noncompliance with medical treatment among youths with insulin-dependent diabetes mellitus. J Am Acad Child Adolesc Psychiatry 31: $1112-1119$

13. Anderson BJ, Ho J, Brackett J, Finkelstein D, Laffel L (1997) Parental involvement in diabetes management tasks: Relationships to blood glucose monitoring adherence and metabolic control in young adolescents with insulin-dependent diabetes mellitus. J Pediatr 130:257-265

14. Wysocki T, Linscheid TR, Taylor AT, Yeates KO, Hough BS, Naglieri JA (1996) Deviation from developmentally appropriate self-care autonomy. Diabetes Care 19:119-125 